\title{
Restless legs syndrome in the elderly
}

\author{
S.T. O'Keeffe, J. Noel and J.N. Lavan \\ Department of Geriatric Medicine, Beaumont Hospital, Dublin 9, Ireland
}

\begin{abstract}
Summary: The prevalence and significance of restless legs syndrome was assessed in 307 patients presenting to an acute-care geriatric medical service. Fifteen patients (5\%) had restless legs syndrome; 13 $(87 \%)$ of these patients had insomnia and $10(67 \%)$ reported troublesome or frequent leg symptoms. Of 147 patients with current insomnia, iron deficiency (serum ferritin $<18 \mathrm{ng} / \mathrm{ml}$ ) was present in $4 / 13(31 \%)$ patients with restless legs and 8/134 (6\%) patients without restless legs $(P<0.025)$. Improvement in symptoms of restless legs was noted with iron repletion.

These findings suggest that restless legs syndome is relatively common in the elderly and causes significant discomfort and sleep disturbance. Iron deficiency is a common and treatable cause.
\end{abstract}

\section{Introduction}

The restless legs syndrome (Ekbom's syndrome) is characterized by unpleasant deep paraesthesias or creeping sensations in the legs which develop at rest and are relieved by movement. ${ }^{1}$ Symptoms either begin or get worse in bed. The cause is unknown in most cases, but restless legs syndrome is common in pregnancy, in iron deficiency states $^{2}$ and in uraemia ${ }^{3}$ and it has been reported in association with many other disorders, including folate deficiency, ${ }^{4}$ chronic respiratory disease,${ }^{5}$ diabetes mellitus, ${ }^{6}$ Parkinson's disease ${ }^{7}$ and malignancy. ${ }^{2}$ The pathogenesis of the syndrome is uncertain, and both peripheral and central mechanisms have been proposed. . $^{1,8,9}$

The prevalence of restless legs in the general population is uncertain, with estimates ranging from less than $1 \%{ }^{10}$ to $15 \% .{ }^{11}$ Several authors have suggested that restless legs syndrome is common in the elderly, ${ }^{12,13}$ but studies using defined criteria have not been reported to date. The purpose of this study was to determine the prevalence and significance of restless legs syndrome in a hospitalbased population of elderly people.

\section{Materials and methods}

We assessed 420 consecutive in-patient and outpatient referrals to an acute-care geriatric medical service. Patients with cognitive impairment (97/ 420 ) and patients taking neuroleptic medications $(16 / 420)$ were excluded. The remaining 307 patients

Correspondence: J.N. Lavan, M.D., F.R.C.P.I., Department of Geriatric Medicine, Beaumont Hospital, Dublin 9, Ireland.

Accepted: 19 April 1993
(174 women and 133 men; median age 76 years, range 65-98 years) were asked about sleep difficulties and about unpleasant sensations affecting both legs at night within the past year.

A detailed questionnaire was completed for all subjects complaining of insomnia, defined as expressed dissatisfaction with the usual duration or quality of sleep, or of nocturnal leg discomfort. These patients had a physical examination, and morning venous blood samples were obtained. Peripheral blood counts were analysed on a Coulter Stkr. A radioimmunoassay (Corning dual label kit) was used to assess vitamin $B_{12}$ and folate in serum and folate in red blood cells. Serum ferritin was analysed on an Abbot IMX.

Anaemia was defined as a haemoglobin $<12 \mathrm{~g} / \mathrm{dl}$ and iron deficiency as a serum ferritin $<18 \mu \mathrm{g} / \mathrm{l}^{14}$ A diagnosis of restless legs syndrome was made if bilateral nocturnal leg discomfort satisfied the following criteria: ${ }^{1,6}$

1. The site included the calf or shin.

2. The sensation was accompanied by an urge to move the legs and was relieved by moving the legs.

3. Symptoms were not of tingling, pins-andneedles, numbness, cramps or burning sensations alone.

Results were analysed by chi-squared test with Yates' correction, and $95 \%$ confidence intervals were calculated where appropriate. ${ }^{15}$

\section{Results}

Fifteen of the 307 patients, 11 women and four men, were diagnosed as having restless legs syndrome, a prevalence of $4.9 \%$ ( $95 \%$ confidence limits $3.1-8.0 \%$ ). The median duration of symptoms was 
3 years (range $<1$ to $>40$ years), and 10 patients had developed symptoms for the first time after the age of 65 years. Three patients had a parent or sibling or both affected by a similar complaint. All patients reported variability in the frequency and severity of symptoms. At the time of the study, two patients were having symptoms every night and a further eight patients had symptoms more than once a week. Symptoms were described as very severe by five patients, moderately severe by four patients, and mild by six patients. Thirteen of the 15 patients with restless legs reported current insomnia (Table I). Nine of these patients reported difficulty going to sleep, and six patients reported difficulty staying asleep. Three patients, two of whom were taking benzodiazepines, reported falling after getting out of bed to relieve the leg discomfort by walking. Thirteen patients had reported their leg symptoms to a doctor but none reported receiving a satisfactory explanation.

One or more medical conditions which may have a role in the development of restless legs syndrome were present in 11 patients: anaemia (4), iron deficiency (4), severe respiratory disease (2), diabetes mellitus (2), malignancy (1), Parkinson's disease (1), vitamin $B_{12}$ deficiency (1), chronic renal impairment. ${ }^{1}$ Two patients had absent ankle reflexes without other evidence of peripheral neuropathy. Among patients with current insomnia, iron deficiency was present in four of $13(31 \%)$ patients with restless legs and in eight of $134(6 \%)$ patients without restless legs $(P<0.025)$.

The four patients with restless legs and iron deficiency were commenced on ferrous sulphate $200 \mathrm{mg}$ three times daily. One patient died before follow-up; the remaining three patients reported substantial improvement in leg symptoms, and it was possible to stop benzodiazepines in two patients who had been using these medications. There was complete resolution of symptoms in the patient with vitamin $B_{12}$ deficiency (serum level $114 \mathrm{ng} / \mathrm{l}$ ) within 1 month of starting vitamin $B_{12}$ treatment.

Table I Prevalence and severity of insomnia in patients with and without restless legs syndrome (RLS)

\begin{tabular}{lcrc}
\hline & $\begin{array}{c}R L S \\
(\mathrm{n}=15)\end{array}$ & $\begin{array}{c}\text { No RLS } \\
(\mathrm{n}=292)\end{array}$ & $\mathrm{P}$ \\
\hline Current insomnia & & & \\
$\quad$ Severe & $10(67)^{*}$ & $64(22)$ & $<0.001$ \\
$\quad$ Not severe & $3(20)$ & $75(26)$ & NS \\
Used to have insomnia & $1(7)$ & $33(11)$ & NS \\
Never had insomnia & $1(7)$ & $120(41)$ & $<0.05$ \\
\hline
\end{tabular}

*Numbers in parentheses are percentages.

\section{Discussion}

The prevalence of restless legs syndrome in this study of elderly patients $(4.9 \%)$ is close to that reported by Ekbom in his survey of 503 normal patients of all ages $(5.2 \%){ }^{2}$ In Ekbom's study, there was no difference in prevalence in different age groups, although the number of patients more than 60 years old was small ( 21 out of 503). Other writers suggest that restless legs syndrome is more common and more severe in older patients. ${ }^{12,16}$ In this study, most patients developed symptoms for the first time in later life. Many of the patients with restless legs detected in previous surveys have experienced only mild symptoms, ${ }^{2}$ and some writers have expressed doubt about the existence of a distinct syndrome in these patients. ${ }^{10}$ Diagnosis of restless legs in this study was based on relatively stringent criteria, and two thirds of patients had frequent and troublesome symptoms. Many of the medical conditions which have been linked with the development of restless legs are more common in the elderly. However, our results, in a hospitalbased survey, may not be applicable to elderly people in the community.

In a study of age-related sleep disorders presenting to a specialist sleep centre, Roehrs and colo leagues diagnosed restless legs syndrome in $33 \%$ of 48 patients over 60 years compared with $18 \%$ of 84 patients aged $40-60$ years and $7 \%$ of 68 patient aged $20-40 .{ }^{17}$ Other writers have concluded that restless legs syndrome is a rare cause of insomnia. ${ }^{16,18}$ In our study, restless legs syndrome was diagnosed in 13 of $152(9 \%)$ patients with current insomnia including 10 of $74(14 \%)$ patients with severe sleep difficulties. Insomnia in patients with restless legs syndrome is not always due to difficulty initiating sleep because of leg dysaesthesias. ${ }^{18}$ Periodic jerking movements of the legs during sleep are common in restless legs syndrome, ${ }^{16}$ and patients are frequently unaware of these movements, which can be associated with a poor quality of sleep and repeated nocturnal awakenings.

Ekbom reported that iron deficiency was common in patients with restless legs, and that iron repletion was effective in relieving symptoms in iron-deficient patients. ${ }^{1}$ Our finding of iron deficiency in $31 \%$ of elderly patients with restless legs and the good response to iron treatment provides further evidence of the importance of studying iron status in these patients. Post-synaptic dopamine D2 receptor blockade has been implicated in the pathogenesis of neuroleptic-induced akathisia, ${ }^{19}$ a condition which is closely related to restless legs syndrome. Iron is an integral part of the dopamine D2 receptor, ${ }^{20}$ suggesting a mechanism for the increased symptoms in patients with an iron-deficient state. Folate deficiency has also 
been reported in association with restless legs ${ }^{4}$ but was not present in any of our patients. We noted a complete resolution of symptoms with vitamin $\mathbf{B}_{12}$ repletion in a patient with $B_{12}$ deficiency without anaemia; an association between restless legs and $\mathbf{B}_{12}$ deficiency has not been noted previously. Two of our patients had absent ankle jerks, perhaps as a result of peripheral neuropathy. ${ }^{21}$ We did not perform nerve conduction studies which may be abnormal in some patients with restless legs syndrome even in the absence of overt clinical neuropathy. ${ }^{3}$

\section{References}

1. Ekbom, K.A. Restless legs syndrome. Neurology 1960, 10: 868-873.

2. Ekbom, K.A. Restless legs. Acta Med Scand 1945, 158 (Suppl 1): $1-123$.

3. Callaghan, N. Restless legs syndrome in uraemic neuropathy. Neurology 1966, 16: 359-361.

4. Botez, M.I. \& Lambert, B. Folate deficiency and restless-legs syndrome in pregnancy. $N$ Engl J Med 1977, 297: 670.

5. Spillance, J.D. Restless legs syndrome in chronic pulmonary disease. Br Med J 1970, 4: 796-798.

6. Banerji, N.K. \& Hurwitz, L.J. Restless legs syndrome, with particular reference to its occurrence after gastric surgery. $\mathrm{Br}$ Med J 1970, 4: 774-775.

7. Strang, R.R. The symptoms of restless legs. Med J Aust 1967 , 1: $1211-1213$.

8. Walters, A.S. \& Hening, W. Clinical presentation and neuropharmacology of restless legs syndrome. Clin Neuropharm 1987, 10: 225-237.

9. Mosko, S., Zetin, M. Glen, S. et al. Self-reported depressive symptomatology, mood ratings, and treatment outcome in sleep disorder patients. J Clin Psychol 1989, 45: 51-60.

10. Feest, T. \& Read, D. Clonazepam: effective treatment for restless legs syndrome in uraemia. Br Med J 1982, 284: 510.

11. Barnes, T.R.E. \& Braude, W.M. Akathisia variants and tardive dyskinesia. Arch Gen Psychiat 1985, 42: 874-878.
Our results suggest that restless legs syndrome is relatively common in the elderly. It is usually associated with significant discomfort and sleep disturbance and may contribute to nocturnal falls, especially in patients taking benzodiazepines. Many patients with restless legs find it difficult to describe their symptoms, ${ }^{1}$ and it is likely that the syndrome is considerably underdiagnosed. It is important that the diagnosis be considered, since specific investigations are indicated to identify secondary and potentially treatable causes such as iron or vitamin $\mathbf{B}_{12}$ deficiency.

12. Zorick, F.J., Roth, T., Hartze, K.M., Piccione, P.M. \& Stephanski, E.J. Evaluation and diagnosis of persistent insomnia. Am J Psychiat 1981, 138: 769-773.

13. Sandyk, $\mathbf{R}$. The restless legs syndrome (Ekbom's syndrome). $S$ Afr Med J 1983, 63: 701-702.

14. Guyatt, G.H., Patterson, C., Ali, M., Singer, J., Levine, M. \& Turpie, I. Diagnosis of iron-deficiency anemia in the elderly. Am J Med 1990, 88: 205-209.

15. Simon, R. Confidence intervals for reporting results of clinical trials. Ann Intern Med 1986, 105: 429-435.

16. Krueger, B.R. Restless legs syndrome and periodic movements of sleep. Mayo Clin Proc 1990, 65: 999-1006.

17. Roehrs, T., Zorick, F., Sicklesteel, J., Wittig, R. \& Roth, T. Age-related sleep-wake disorders at a sleep disorder clinic. $J$ Am Geriatr Soc 1983, 31: 364-370.

18. Gillin, J.C. \& Byerley, W.F. The diagnosis and management of insomnia. N Engl J Med 1990, 322: 239-248.

19. Brown, K.W., Glen, S.E. \& White, T. Low serum iron status and akathisia. Lancet 1987, 1: 1234-1235.

20. Ben-Shacher, D., Finburg, J.P.M. \& Youdim, M.B.H. Effects of iron chelators on dopamine $\mathrm{D}_{2}$ receptors. $J$ Neurochem 1985, 45: 999-1005.

21. Ipallomeni, M., Kenny, R.A., Flynn, M.D., Kraenzlin, M. \& Pallis, C.A. The elderly and their ankle jerks. Lancet 1984, 1: 670-672. 